\title{
ALGUNS DADOS DE RENDIMENTO DE RAMÍ EM CAULE, CASCA E FIBRA
}

J. C. Medina

\section{INTRODUÇÃO}

A planta ramí ou "tschouma", botanicamente classificada como Boehmeria nivea Hook et Arn., de cujo caule se extrai a casca conhecida comercialmente como "rami" ou "china grass", e que contem uma fibra liberiana de natureza pecto-celulósica, pertence à família Urticaceae, ou família das urtigas. É cultivada principalmente na China e em Formosa. Outra espécie tambem cultivada em certa escala, principalmente nas Indias Orientais, partes da f́ndia e Assam, e no México, é a $B$. utilis, vulgarmente conhecida pelo nome de "rhéa". Estas duas espécies podem ser facilmente distinguidas, visto que a $B$. nivea apresenta a página inferior das folhas provida de uma penugem branco-prateada, que é ausente na $B$. utilis.

Deve-se considerar o sul da China como o centro da mais velha cultura de ramí, e, provavelmente, como o seu lugar de origem. As primeiras citações referentes ao aproveitamento da fibra na China datam do $\mathrm{X}$ ao $\mathrm{V}$ séculos $A$. C. Na literatura do III ao II séculos $A$. C. encontramse indicações sobre a sua cultura em jardins, e, nessa época, como ainda praticado, os chineses utilizavam facas de bambú para separar as matérias pécticas da casca.

A partir da China, a cultura irradiou, muito mais tarde, para as Ilhas Filipinas, Formosa, Sonda, e, em seguida, para as Índias, Japão e Coréia. Desde o início do século XIX, a fibra de ramí adquiriu certa importância no mercado mundial, iniciando-se então tentativas de introdução e aclimatação da planta em diversos paises de outros continentes.

Em nosso meio, as primeiras tentativas de cultura, como planta textil, são relativamente recentes, mas, a-pesar disso, a área cultivada já é de certo modo extensa, malgrado os escassos conhecimentos existentes

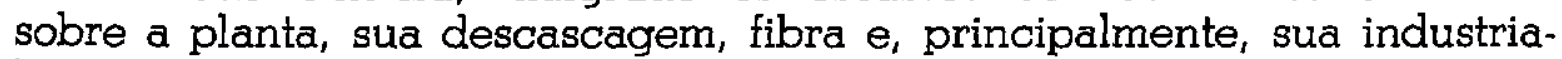
lização.

A-pesar do elevado número de artigos já publicados sobre ramí, a literatura respectiva é bastante falha quanto a dados positivos no sentido de um melhor conhecimento desta planta fibrosa. Com o fito de con- 
tribuir para o estudo dessa promissora Urticaceae, apresentamos, no presente artigo, os resultados médios obtidos com amostras de ramí coletadas em dois ensaios de adubação. Estes ensaios, em blocos ao acaso de 10 tratamentos em 6 repetições, estão localizados nas Estações Experimentais de Campinas e Ribeirão-Preto. Se bem que sejam dados de ramí de primeiro corte, as relações apresentadas hão-de, provavelmente, modificar-se muito pouco nos cortes subsequentes, de modo que poderão ser tomadas como básicas. Todavia, pretendemos continuar a retirada de amostras nos cortes seguintes, de modo a poder publicar mais tarde dados mais completos. Nessa ocasião tambem publicaremos os resultados obtidos com a adubação, assim como resultados de um estudo de resistência das fibras e o efeito da adubação nesta propriedade mecânica.

\section{AMOSTRA}

A coleta de amostra, feita na ocasião do corte e pesagem das produções dos tratamentos, foi executada com a maior imparcialidade e uniformidade possiveis. Em Campinas, o número de caules tomados em cada amostra foi de 50, e em Ribeirão-Preto foi de 25. Essa diferença nas amostras das duas localidades foi porque determinamos, posteriormente, que 25 caules representavam uma boa amostra e tambem se ajustavam melhor às nossas condições, pela falta de operário para executar a descascagem manual rapidamente.

Obtida a amostra, esta foi imediatamente pesada, conseguindo-se assim o peso de caules verdes mais as folhas. Em seguida, foi feita a desfolhagem, pesando-se somente os caules verdes. $\mathrm{Na}$ retirada da casca procedemos de dois modos. Em Campinas, devido à falta de operário no momento, a operação de descascagem foi efetuada mais tarde, quando os caules já estavam completamente secos. Em Ribeirão-Preto, a descascagem foi efetuada logo depois do corte, quando os caules estavam ainda verdes, pesando-se a casca verde obtida, dado este que não se pode obter com as amostras de Campinas. Todavia, esta diferença no momento da descascagem resultou em dados bastante interessantes. Em Campinas, as percentagens de casca seca e fibra não branqueada foram sempre superiores às determinadas nas amostras de Ribeirão-Preto. Provavelmente estes resultados indicam que uma máquina descorticadora tenha que executar a operação sobre caules secos, dada a possibilidade de um maior rendimento em casca e fibra do que sobre caules verdes. Convem salientar que a opinião corrente sobre a descorticação nestas condições não é exata. A descorticação sobre caules secos não dá, absolutamente, fibra manchada, desde que os caules sejam desfolhados e secados em lugar bem arejado.

Cada amostra de casca seca, tanto de Campinas como de RibeirãoPreto, foi igualmente desgomada, pesando-se depois a fibra desgomada obtida. Nesta operação cada amostra foi separadamente digerida em uma solução de $\mathrm{NaOH}$ a $2,5 \%$, durante 3 horas, em autoclave funcionando a 1,5 atmosferas. 


\section{RESULTADOS}

Os resultados obtidos com as amostras de Campinas e RibeirãoPreto estão dispostos na Tabela I, que acompanha o presente trabalho, representando cada dado a média de amostra das seis repetições que formam cada ensaio. $O$ exame desta revela que, provavelmente, as adubações não exerceram nenhum efeito sobre as quantidades de casca e fibra, visto que os resultados das amostras dos tratamentos adubados pouco diferem dos dados dos controles, tanto nas amostras médias de uma localidade como de outra. É interessante notar a diferença nas percentagens de casca seca e fibra entre as amostras das duas localidades, consoante já foi dito em outra parte deste trabalho. Outro fato tambem interessante é a quase igualdade de peso entre as amostras de Campinas e Ribeirão-Preto, pois as amostras daquela localidade teem o dobro de caules das amostras desta.

Com os resultados obtidos podemos resumir as seguintes observações preliminares:

1 - As folhas e extremidades representam cerca de 55 a $60 \%$ do peso total das plantas verdes colhidas.

2 - Nas amostras de Campinas as percentagens médias de caules verdes e caules secos representam cerca de 45 e $14 \%$ do peso total das plantas verdes colhidas.

3 -- Nas amostras de Ribeirão-Preto as percentagens médias de caules verdes desfolhados e casca verde representam 40 e $6 \%$ do peso total das plantas verdes colhidas.

4 - As percentagens médias de casca seca, em relação ao peso total de plantas verdes colhidas, nas amostras de Campinas e de RibeirãoPreto, são de 2,3 e 1,6\%, respectivamente. Esta diferença provavelmente se deve ás condições em que foi executada a descascagem dos caules. Em Campinas, a descascagem foi efetuada sobre caules secos, ao passo que em Ribeirão-Preto foi efetuada sobre caules verdes.

5 -. As amostras de Campinas mostram uma percentagem média de fibra pura, em relação ao peso total de plantas verdes colhidas, de cerca de 1\%, enquanto as de Ribeirão-Preto, aproximadamente, de 0,7\%.

6 - Tanto nas amostras de Campinas como nas de Ribeirão-Preto, a percentagem média de fibra pura em casca seca é de cerca de $45 \%$, isto é, a fibra bruta perde durante a operação de desgomagem cerca de $55 \%$ de seu peso.

7 -- Finalmente, tanto a fibra obtida de casca retirada de caules verdes como a de caules secos apresenta o mesmo aspecto depois do branqueamento.

\section{SUMMARY}

1. In the present article the author gives preliminary results on average composition on samples of ramie plant.

2. The leaves and tops represent from 55 to 60 per cent of the total weight of green plants cut. 
3. In the samples from Campinas the average percentages of green and dry stalks less tops and leaves are about 45 and 14 per cent of the total weight of green plants cut.

4. In the samples from Ribeirão-Preto the average percentages of green stalks defoliated and topped and of green ribbons are about 40 and 6 per cent respectively of the total weight of green plants cut.

5. The average percentage of dry ribbons in the samples from Campinas and RibeirãoPreto are about 2,3 and 1,6 per cent respectively of all green plants cut. Perhaps this difference is due to the conditions under which the decortication was carried out. In Campinas it was made on dry stalks while in Ribeirão-Preto on green ones.

6. The samples from Campinas showed an average percentage of pure fiber in all green plants cut of about 1 per cent while those from Ribeirão-Preto nearly 0,7 per cent.

7. In both the samples from Campinas and Ribeirão-Preto the average percentage of pure tiber in dry ribbons is about 45 per cent, that is, the raw fiber or "China grass" lost during degumming about 55 per cent of its weight.

8. Finally the fiber obtained from ribbons stripped of either the green or the dry stalks presents the same aspect after the bleaching operation. 


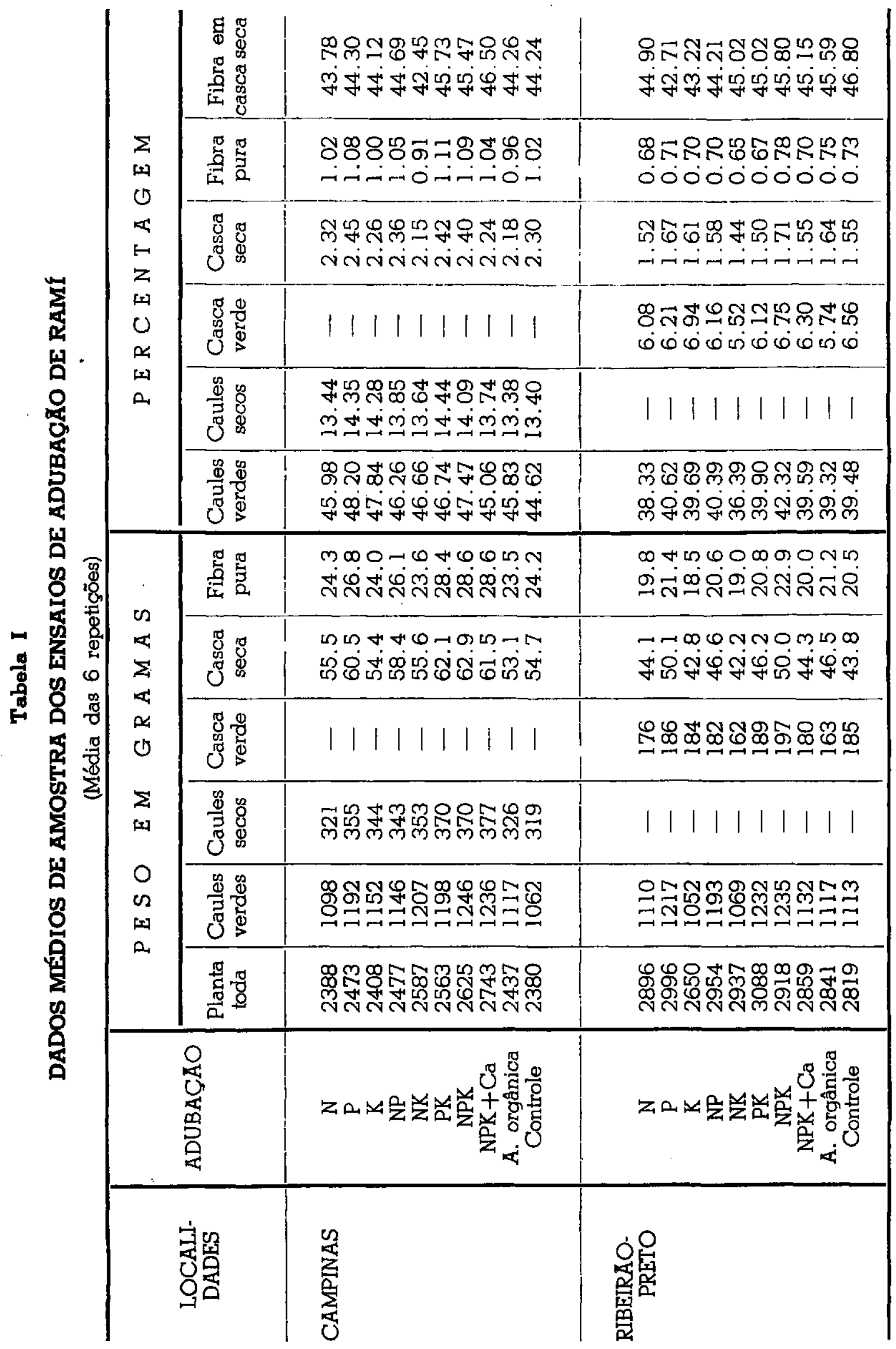

